\title{
1\% ACETIC ACID SOLUTION FOR BURN WOUND CARE
}

Hajská M., Slobodníková ., Koller J. (mariannahajska@gmail.com)

Medical faculty of Comenius University, Bratislava, Slovak Republic

\begin{tabular}{|c|c|}
\hline$\frac{\text { ACETIC }}{\text { ACID: }} \stackrel{\mathrm{H}}{\mathrm{H}-\mathrm{C}_{\mathrm{H}}^{\mathrm{C}}-\mathrm{C}_{\mathrm{C}}^{\mathrm{O}} \mathrm{OH}}$ & $\begin{array}{l}\text { a weak acid, liquid in ambient pressure and temperature, present in vinegar } \\
\text { used in medicine for thousands of years, as solution in } 0,25-5 \% \text { concentration } \\
\text { can be inexpensively produced, easily autoclaved and stored }\end{array}$ \\
\hline
\end{tabular}

\section{AIM:}

1) evaluate the antibacterial efficacy of $1 \%$ acetic acid using in vitro burn wound models

2) test the possible toxicity of $1 \%$ acetic acid on 3 T3 cells and dermal fibroblasts

\section{ANTIBACTERIAL EFFICACY:}

$>7$ multidrug-resistant bacteria isolated from burn wounds

$>4$ models ( $\mathrm{A}$ - fresh wound, B - 4hrs wound, C - 6hrs wound, D - 24hrs wound (biofilm model)

$>1 \%$ Acetic acid $1 \mathrm{ml}$ applied on gauze - acted $24 \mathrm{hrs}$ in every model

\begin{tabular}{|l|c|c|c|c|c|c|c|}
\hline & P.aeruginosa 1 & P.aeruginosa 2 & MRSA & E.coli & E.faecalis & S.haemolyticus & Acinetobacter sp. \\
\hline Model A & $0,00 \mathrm{E}+00$ & $0,00 \mathrm{E}+00$ & $0,00 \mathrm{E}+00$ & $3,00 \mathrm{E}+03$ & $4,00 \mathrm{E}+03$ & $0,00 \mathrm{E}+00$ & $0,00 \mathrm{E}+00$ \\
\hline Model B & $0,00 \mathrm{E}+00$ & $0,00 \mathrm{E}+00$ & $7,00 \mathrm{E}+03$ & $1,00 \mathrm{E}+08$ & $4,00 \mathrm{E}+05$ & $0,00 \mathrm{E}+00$ & $0,00 \mathrm{E}+00$ \\
\hline Model C & $0,00 \mathrm{E}+00$ & $0,00 \mathrm{E}+00$ & $3,00 \mathrm{E}+04$ & $1,00 \mathrm{E}+08$ & $1,04 \mathrm{E}+06$ & $0,00 \mathrm{E}+00$ & $0,00 \mathrm{E}+00$ \\
\hline Model D & $4,00 \mathrm{E}+07$ & $1,00 \mathrm{E}+08$ & $1,00 \mathrm{E}+08$ & $1,00 \mathrm{E}+08$ & $1,00 \mathrm{E}+08$ & $3,70 \mathrm{E}+07$ & $7,70 \mathrm{E}+07$ \\
\hline
\end{tabular}

$\square$ Model A $\square$ Model B $\square$ Model C $\square$ Model D

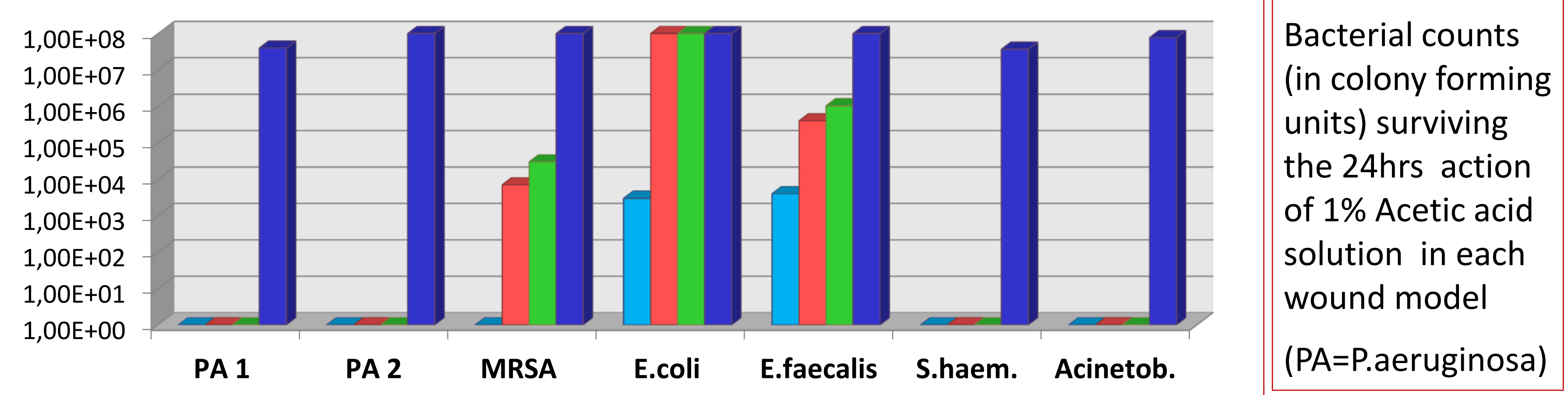

\section{CYTOTOXICITY TESTING:}

$>$ murine 3 T3 cells and human dermal fibroblasts (DF) were counted following $24 \mathrm{hrs}$ action of $1 \%$ acetic acid solution $>$ as control samples $20 \%$ sodium dodecyl sulfate $(20 \%$ SDS) , sterile gauze and no agent were used
aT3 Cells DF cells

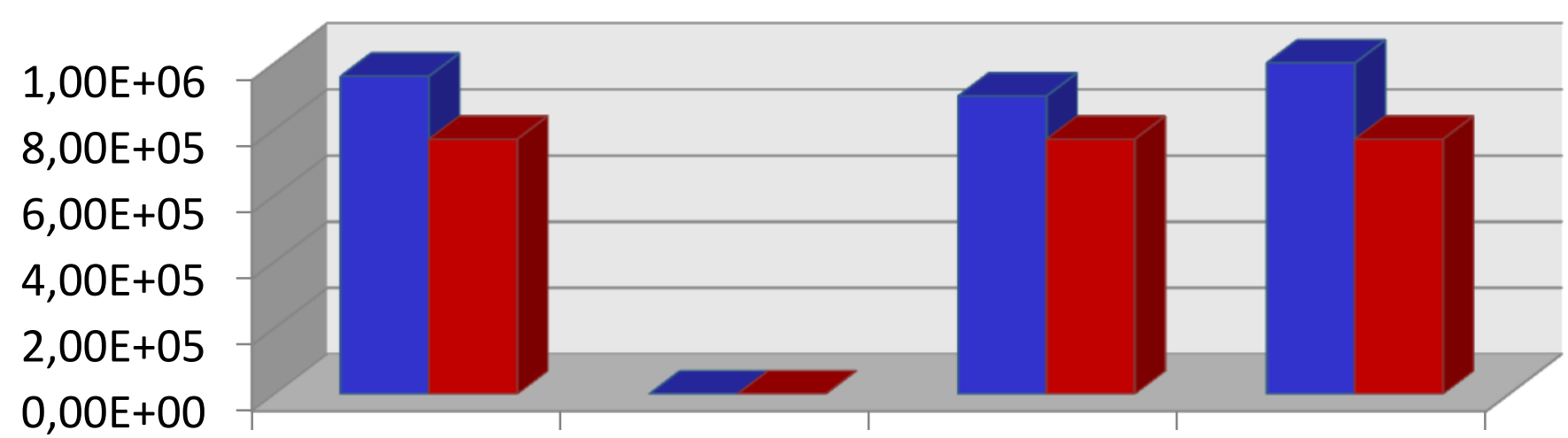

AA1\% 20\%SDS Gauze No agent

CONCLUSIONS: $1 \%$ acetic acid thanks to its good antimicrobial effect and no cytotoxicity can be recommended as a cheap and accessible antimicrobial agent for burn wound care. 